\title{
The Possibility of Using Endophytic Micromycetes for Increasing Plant Metal Resistance
}

\section{Irina Bukharina and Nadezhda Islamova}

Udmurt State University, Russia

\section{ORCID}

Irina Bukharina; ORCID: 0000-0001-8084-2547

\begin{abstract}
The aim of this research was to study the effect of inoculation with the Cylindrocarpon magnusianum endotrophic micromycete on the physiological and biochemical parameters of tomato test plants under the action of heavy metal salts. The plants were inoculated with the fungus culture (control population) and populations of this fungus preliminarily adapted to the action of the stress factor. Then, inoculated plants were grown under control conditions and on substrates with different concentrations of heavy metal salts (zinc, copper, lead and chromium). After the plants were inoculated with the control population of the C. magnusianum fungus, a stimulating effect increasing the plants' resistance to the action of the heavy metal salts was not detected. When the plants were inoculated with adapted populations of the C. magnusianum fungus, adaptive reactions of the plants associated with the content of photosynthetic pigments in the leaves and the formation of plant biomass were significantly manifested. Under these conditions, a more intense development of fungal infection in plant roots was observed in contrast to the use of the control fungal population. These findings therefore demonstrated an effective partnership between the $C$. magnusianum fungus and the root system of plants under extreme conditions for plant life.
\end{abstract}

Corresponding Author: Irina Bukharina; email:

buharin@udmlink.ru

Dates

Published 13 January 2022

Publishing services provided by Knowledge E

(c) Irina Bukharina and

Nadezhda Islamova. This article

is distributed under the terms of the Creative Commons

Attribution License, which permits unrestricted use and redistribution provided that the original author and source are credited

Selection and Peer-review under the responsibility of the 8th Scientific and Practical Conference Conference Committee.

Keywords: Cylindrocarpon magnusianum, micromycetes, heavy metals, inoculation, biochemical indicators

\section{Introduction}

Currently, the scientific community has increased the interest in studying the role of consortium ties of plants with root micromycetes. Certain successes have been achieved in studying the role of endomycorrhiza and its most common form - arbuscular mycorrhiza (AM), which is typical for most modern phylogenetic groups of plants and is introduced in all biomes of the globe. It is formed by fungi belonging to the Glomeromycotina subdivision of the Mucoromycota division [1]. But the use of AMF in crop production is limited, which is a consequence of their obligate symbiotrophy [2]. In this regard, the study of the role of other groups of root micromycetes of endophytes and their individual representatives in the formation of resistance mechanisms in higher plants is of particular interest. Historically, two groups of endophytes ( $\square$ /avicipitaceous and 
Nonclavicipitaceous) were distinguished on the basis of phylogeny and signs of the life cycle $[3,4] .$. In general, this heterogeneous group of fungi can have a strong effect on plant communities by ensuring the resistance of plants to abiotic and biotic stress. The studies of the endophytes role in the formation of plants' resistance to metals, including crops [3-7], and with regard to chemical elements that are extremely dangerous for plants [8-12]. are of particular interest. A number of studies are aimed at studying the possibility of using micromycetes as herbicides [13-17].

One of the promising micromycetes is the endophyte of Cylindrocarpon magnusianum Wollenw. [18-20]. It was established that its metabolites can be used in the fight against nematodes [18], it is able to grow under conditions of high oil content in the soil $[18,19]$. During a series of author's experiments conducted with C. magnusianum it was found that the culture of this fungus is able to withstand the high osmotic pressure while maintaining the growth of cultural mycelium. And experiments with plants inoculated with this fungus showed the possibility of its use as an agent for increasing the salt tolerance of plants [20, 21].

The aim of our research was to study the effect of inoculation with the C. magnusianum fungus culture on the formation of adaptive plant responses to the action of heavy metal salts in the substrate (using the test culture of Solánum lycopérsicum tomato as an example).

\section{Material and Methods}

The culture of $C$. magnusianum was isolated from the root system of woody plants (Acer negundo L. in a good living condition) which grows for a long time in urban soils with a high content of heavy metal salts (highway plantings, sanitary protection zone of industrial enterprise «lzhstal», Izhevsk, Udmurtia) The fungus is cultivated on a nutrient medium outside the root system of plants.

The species affiliation of the fungus was established by microscopy and molecular analysis of DNA in the laboratory of the Leibniz Institute of Vegetable and Decorative Crops (Berlin) [21].

According to the schematic course of experiment, the fungus isolates (populations) adapted to substrates with the addition of different concentrations of heavy metal salts $(H M)$ were prepared, $m g / l: A_{0}$ - control; $A_{1}$ - on a substrate with $Z n_{100} ; A_{2}-C_{50} ; A_{3}-$ $\mathrm{Cu}_{100} ; \mathrm{A}_{4}-\mathrm{Cu}_{150} ; \mathrm{A}_{5}-\mathrm{Pb}_{10} ; \mathrm{A}_{6}-\mathrm{Pb}_{50} ; \mathrm{A}_{7}-\mathrm{Cr}_{2,5} ; \mathrm{A}_{8}-\mathrm{Cr}_{10}$. Then, suspension cultures of these populations were prepared (spore content -3 million units / ml; mycelium fragments -200 units $/ \mathrm{ml}$ ) and the plants were inoculated by irrigation of seedlings 
during the pricking period. The experiment included the following options: 1) inoculated tomatoes (inoculation with control isolate $A_{0}$ ) were grown on substrates with different contents of heavy metal salts, mg / I: $\mathrm{B}_{0}$ - control - without $\mathrm{HM} ; \mathrm{B}_{1}-\mathrm{Zn}_{100} ; \mathrm{B}_{2}-\mathrm{Cu}_{50}$; $\left.\mathrm{B}_{3}-\mathrm{Cu}_{100} ; \mathrm{B}_{4}-\mathrm{Cu}_{150} ; \mathrm{B}_{5}-\mathrm{Pb}_{10} ; \mathrm{B}_{6}-\mathrm{Pb}_{50} ; \mathrm{B}_{7}-\mathrm{Cr}_{2,5} ; \mathrm{B}_{8}-\mathrm{Cr}_{10} ; 2\right)$ tomatoes inoculated with fungal populations adapted to heavy metals $\left(A_{1}-A_{8}\right)$ were grown on substrates without application $\left(B_{0}\right)$ and with the addition of $H M$ salts $\left(B_{1}-B_{8}\right)$. The repetition of options for the experiment is fourfold. The substrate was a mixture of peat low ash and sand 1: 2. Plants were grown in a «BinderKBWF720» climatic chamber (Germany) under optimal tomato culture conditions (substrate humidity $75 \%$, illumination 20,000 lux (16 hours a day), daytime air temperature $23^{\circ} \mathrm{C}$, at night $-19^{\circ} \mathrm{C}$ ). We used a dwarf variety of tomato "Balcony Miracle." Plants were grown for 4 months before the onset of fruiting stage. Experimental studies were conducted during 2017-2019 in the scientific laboratory "Environmental Biotechnology" of the Udmurt State University.

At the end of the experiment the endophyte fungi development in the roots by light microscopy was evaluated [22]. The assessment of plant resistance was carried out on the basis of: the content of nitrates in the leaves - by the ionometric method (GOST 29270-95); biomass and the percentage of dry matter in the aerial part and the root system of plants by the weight method (GOST 28561-90); photosynthetic pigments in the leaves of the middle tier (chlorophylls $a$ and $b$, carotenoids) by spectrophotometric method in acetone extracts (absorption of 662, 644 and $440.5 \mathrm{~nm}$, respectively), the calculation of the pigment concentration was carried out according to the Wetstein- Hill equations.

Mathematical processing of materials was carried out using the statistical package "Statistica 6.0 " by descriptive statistics methods. Significant differences were established at $\square \otimes 0,05$.

\section{Results and Discussion}

The analysis of the results showed (Fig. 1-3). The results of experimental variants using non-biogenic chemical elements (chromium and lead) were of particular interest. When plants were inoculated with the control fungal population and cultured on $\mathrm{Pb}_{10}$ substrate, a true decrease in chlorophyll $a$ and $b$ was observed, on $\mathrm{Pb}_{50}$ substrate chlorophyll $a$ was observed, while there was no significant decrease in carotenoid content.

The use of adapted fungus populations when growing plants on BO caused an increase in the content of all studied pigments, but when they were grown on substrates 


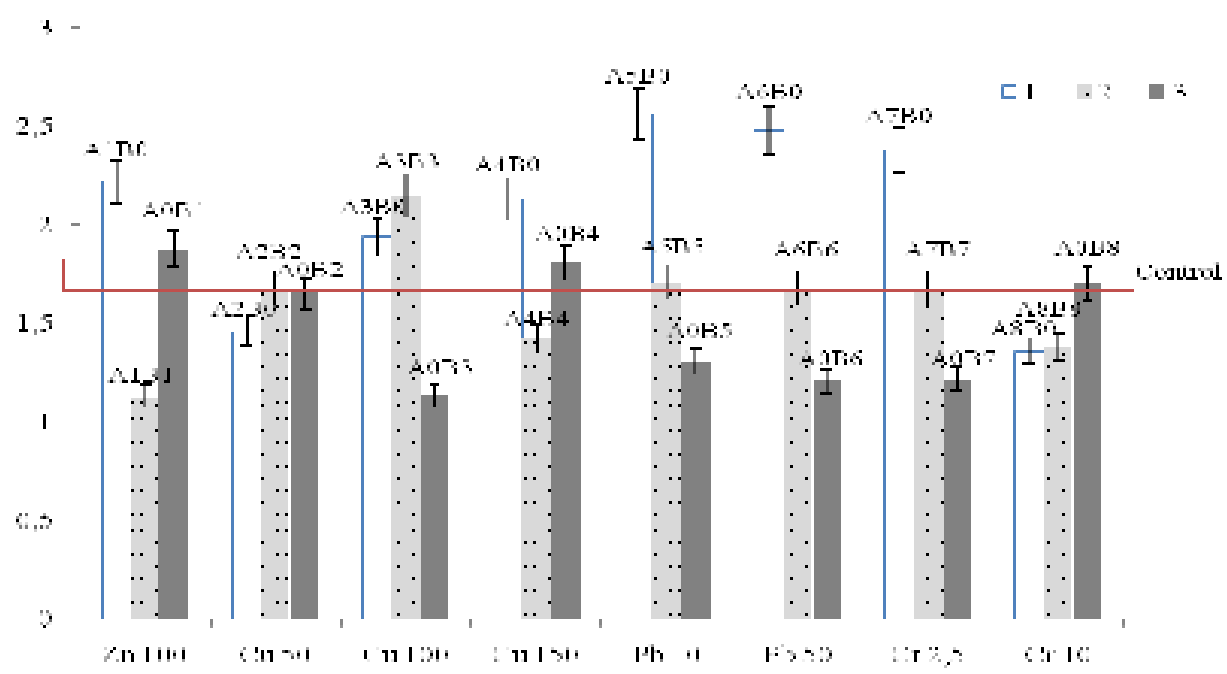

Figure 1: The content of chlorophyll $a$ in the leaves of inoculated tomato plants under conditions of different concentrations of heavy metals in the substrate: 1 - fungus population $\left(A 1-Z_{100} ; A 2-\mathrm{Cu}_{50} ; \mathrm{A}_{3}-\mathrm{Cu}_{100}\right.$; $\mathrm{A} 4-\mathrm{Cu}_{150} ; \mathrm{A} 5-\mathrm{Pb}_{10} ; \mathrm{A} 6-\mathrm{Pb}_{50} ; \mathrm{A} 7-\mathrm{Cr}_{2,5} ; \mathrm{A} 8-\mathrm{Cr}_{10}$ ) + substrate without heavy metals (B0); 2 - fungus population $\left(\mathrm{A} 1-\mathrm{Zn}_{100} ; \mathrm{A} 2-\mathrm{Cu}_{50} ; \mathrm{A} 3-\mathrm{Cu}_{100} ; \mathrm{A} 4-\mathrm{Cu}_{150} ; \mathrm{A} 5-\mathrm{Pb}_{10} ; \mathrm{A} 6-\mathrm{Pb}_{50} ; \mathrm{A} 7-\mathrm{Cr}_{2.5} ; \mathrm{A} 8-\mathrm{Cr}_{10}\right)+$ substrate with heavy metals, $\mathrm{mg} / \mathrm{l}\left(\mathrm{B} 1-\mathrm{Zn}_{100} ; \mathrm{B} 2-\mathrm{Cu}_{50} ; \mathrm{B} 3-\mathrm{Cu}_{100} ; \mathrm{B} 4-\mathrm{Cu}_{150} ; \mathrm{B} 5-\mathrm{Pb}_{10} ; \mathrm{B} 6-\mathrm{Pb}_{50} ; \mathrm{B} 7-\right.$ $\left.\mathrm{Cr}_{2,5} ; \mathrm{B} 8-\mathrm{Cr}_{10}\right) ; 3$ - control population fungi $(\mathrm{AO})+$ substrate with heavy metals $\left(\mathrm{B} 1-\mathrm{Zn}_{100} ; \mathrm{B} 2-\mathrm{Cu}_{50}\right.$; $\mathrm{B} 3-$ $\left.\mathrm{Cu}_{100} ; \mathrm{B} 4-\mathrm{Cu}_{150} ; \mathrm{B} 5-\mathrm{Pb}_{10} ; \mathrm{B} 6-\mathrm{Pb}_{50} ; \mathrm{B} 7-\mathrm{Cr}_{2,5} ; \mathrm{B} 8-\mathrm{Cr}_{10}\right)$; $\mathrm{AOBO}-$ control population of the fungus on the substrate without heavy metals (a rectangle denotes the confidence interval of the average values of the indicator for this option). On the Y-axis - Content of chlorophyll $a, \mathrm{mg} / \mathrm{g}$ "; on the X-axis - Content of heavy metals in the substrate, $\mathrm{mg} / \mathrm{l}$ ".

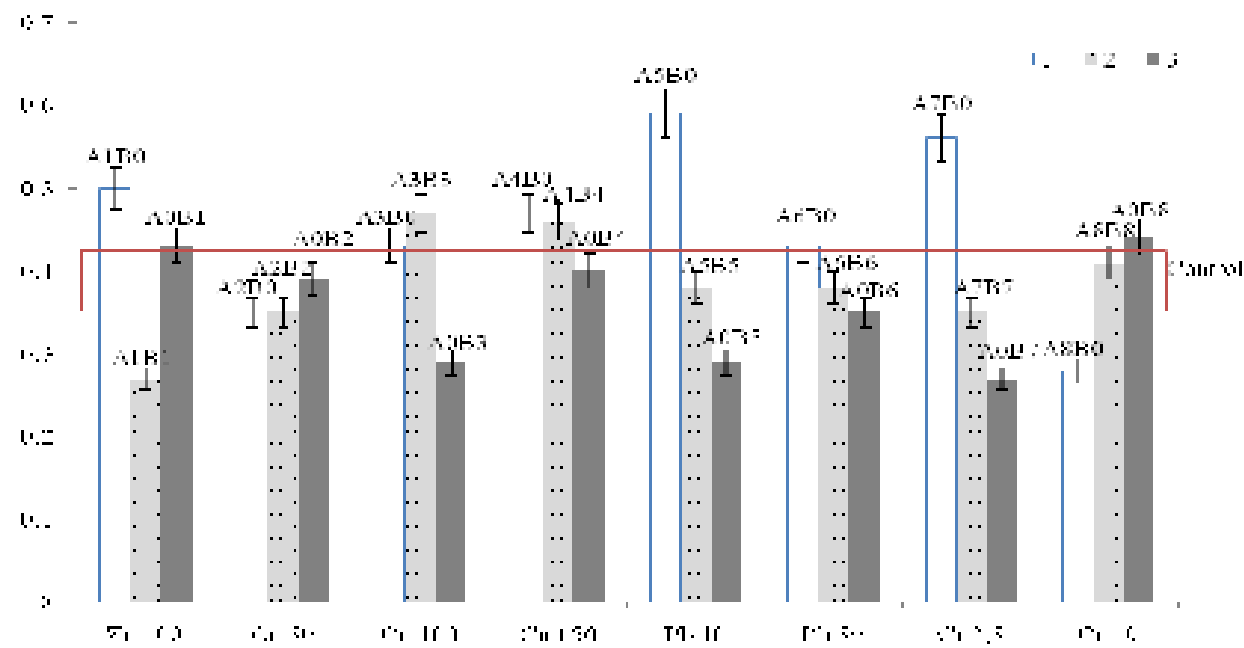

Figure 2: The content of chlorophyll $b$ in the leaves of inoculated tomato plants under conditions of different concentrations of heavy metals in the substrate: 1 - fungus population ( $\mathrm{A} 1-\mathrm{Zn}_{100} ; \mathrm{A} 2-\mathrm{Cu}_{50} ; \mathrm{A} 3-\mathrm{Cu}_{100}$; $\left.\mathrm{A} 4-\mathrm{Cu}_{150} ; \mathrm{A} 5-\mathrm{Pb}_{10} ; \mathrm{A} 6-\mathrm{Pb}_{50} ; \mathrm{A} 7-\mathrm{Cr}_{2,5} ; \mathrm{A} 8-\mathrm{Cr}_{10}\right)$ + substrate without heavy metals (B0); 2 - fungus population (A1- $\left.\mathrm{Zn}_{100} ; \mathrm{A} 2-\mathrm{Cu}_{50} ; \mathrm{A} 3-\mathrm{Cu}_{100} ; \mathrm{A} 4-\mathrm{Cu}_{150} ; \mathrm{A} 5-\mathrm{Pb}_{10} ; \mathrm{A} 6-\mathrm{Pb}_{50} ; \mathrm{A} 7-\mathrm{Cr}_{2,5} ; \mathrm{A} 8-\mathrm{Cr}_{10}\right)+$ substrate with heavy metals, $\mathrm{mg} / \mathrm{l}\left(\mathrm{B} 1-\mathrm{Zn}_{100} ; \mathrm{B} 2-\mathrm{Cu}_{50} ; \mathrm{B} 3-\mathrm{Cu}_{100} ; \mathrm{B} 4-\mathrm{Cu}_{150} ; \mathrm{B} 5-\mathrm{Pb}_{10} ; \mathrm{B} 6-\mathrm{Pb}_{50} ; \mathrm{B} 7-\right.$ $\mathrm{Cr}_{2,5}$; $\left.\mathrm{B} 8-\mathrm{Cr}_{10}\right) ; 3$ - control population fungi $(\mathrm{AO})+$ substrate with heavy metals $\left(\mathrm{B} 1-\mathrm{Zn}_{100} ; \mathrm{B} 2-\mathrm{Cu}_{50}\right.$; $\mathrm{B} 3-$ $\left.\mathrm{Cu}_{100} ; \mathrm{B} 4-\mathrm{Cu}_{150} ; \mathrm{B} 5-\mathrm{Pb}_{10} ; \mathrm{B} 6-\mathrm{Pb}_{50} ; \mathrm{B} 7-\mathrm{Cr}_{2,5} ; \mathrm{B} 8-\mathrm{Cr}_{10}\right) ; \mathrm{AOBO}-$ control population of the fungus on the substrate without heavy metals (a rectangle denotes the confidence interval of the average values of the indicator for this option). On the Y-axis - Content of chlorophyll $b, \mathrm{mg} / \mathrm{g}$ "; on the X-axis - Content of heavy metals in the substrate, $\mathrm{mg} / \mathrm{l}$ ". 


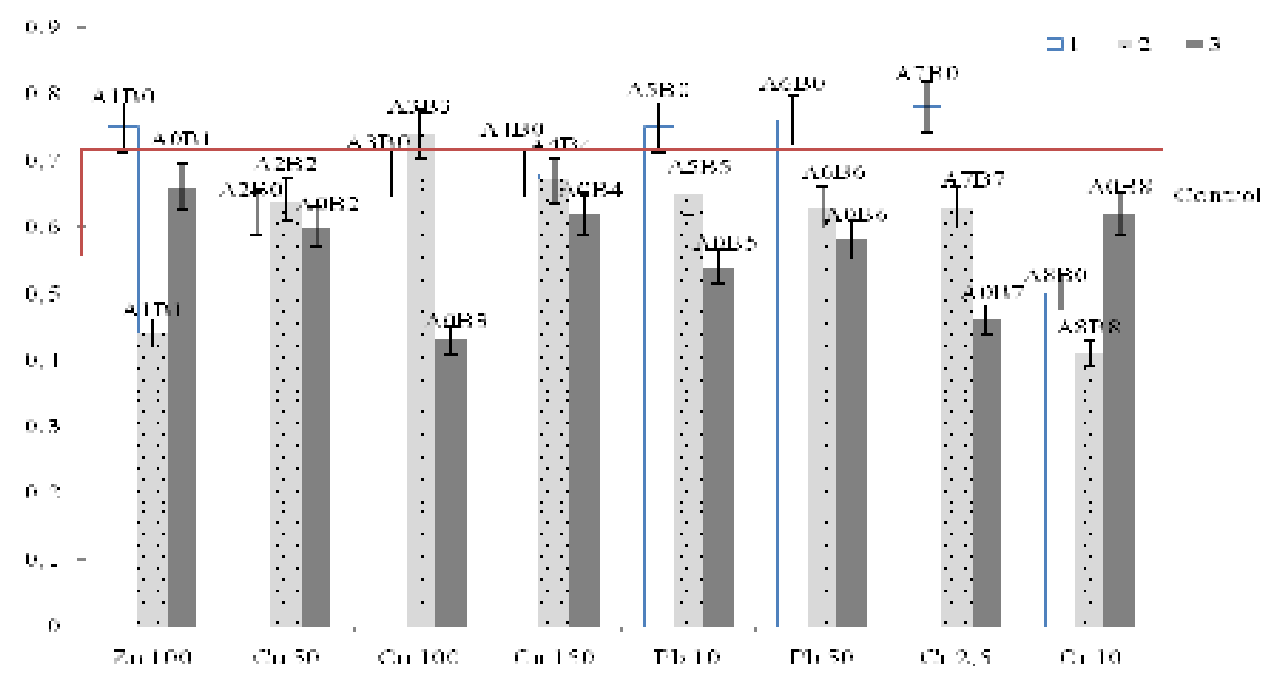

Figure 3: The content of carotenoids in the leaves of inoculated tomato plants under conditions of different concentrations of heavy metals in the substrate: 1 - fungus population $\left(A 1-Z_{100} ; A 2-C_{50} ; A 3-\mathrm{Cu}_{100}\right.$; $\mathrm{A} 4-\mathrm{Cu}_{150} ; \mathrm{A} 5-\mathrm{Pb}_{10} ; \mathrm{A} 6-\mathrm{Pb}_{50} ; \mathrm{A} 7-\mathrm{Cr}_{2,5} ; \mathrm{A} 8-\mathrm{Cr}_{10}$ ) + substrate without heavy metals (B0); 2 - fungus population $\left(\mathrm{A} 1-\mathrm{Zn}_{100} ; \mathrm{A} 2-\mathrm{Cu}_{50} ; \mathrm{A} 3-\mathrm{Cu}_{100} ; \mathrm{A} 4-\mathrm{Cu}_{150} ; \mathrm{A} 5-\mathrm{Pb}_{10} ; \mathrm{A} 6-\mathrm{Pb}_{50} ; \mathrm{A} 7-\mathrm{Cr}_{2,5} ; \mathrm{A} 8-\mathrm{Cr}_{10}\right)+$ substrate with heavy metals, $\mathrm{mg} / \mathrm{l}\left(\mathrm{B} 1-\mathrm{Zn}_{100} ; \mathrm{B} 2-\mathrm{Cu}_{50} ; \mathrm{B} 3-\mathrm{Cu}_{100} ; \mathrm{B} 4-\mathrm{Cu}_{150} ; \mathrm{B} 5-\mathrm{Pb}_{10} ; \mathrm{B} 6-\mathrm{Pb}_{50} ; \mathrm{B} 7-\right.$ $\mathrm{Cr}_{2,5}$; $\left.\mathrm{B} 8-\mathrm{Cr}_{10}\right) ; 3$ - control population fungi $(\mathrm{AO})+$ substrate with heavy metals $\left(\mathrm{B} 1-\mathrm{Zn}_{100} ; \mathrm{B} 2-\mathrm{Cu}_{50}\right.$; $\mathrm{B} 3-$ $\mathrm{Cu}_{100} ; \mathrm{B} 4-\mathrm{Cu}_{150} ; \mathrm{B} 5-\mathrm{Pb}_{10} ; \mathrm{B} 6-\mathrm{Pb}_{50} ; \mathrm{B} 7-\mathrm{Cr}_{2,5}$; $\left.\mathrm{B} 8-\mathrm{Cr}_{10}\right)$; AOBO - control population of the fungus on the substrate without heavy metals (a rectangle denotes the confidence interval of the average values of the indicator for this option). On the Y-axis - Content of carotenoids, $\mathrm{mg} / \mathrm{g}$ "; on the X-axis - Content of heavy metals in the substrate, $\mathrm{mg} / \mathrm{l}$."

with the addition of lead salts, no significant changes were revealed in comparison with the control.

Inoculation of plants with the control fungus population led to a significant decrease in the percentage of dry matter in the aerial parts of plants (table). When using adapted populations and when growing plants on a control substratum, a decrease in biomass of the root system was noted, and when cultivating plants on substrates with $\mathrm{Pb}_{10}$ and $\mathrm{Pb}_{50}$, the biomass and dry matter content did not have significant changes, but an increase in the content of nitrates in the leaves was noted.

In all variants with lead, the fungal infection in the root system of plants had high development rates, the highest - in the variants of Control / $\mathrm{Pb}_{10}, \mathrm{~Pb}_{50}$ and $\mathrm{Pb}_{10}, \mathrm{~Pb}_{50} /$ Control.

In variants with chromium inoculation of plants with a control population when they were cultured on a substrate with $\mathrm{Cr}_{2,5}$ led to a significant decrease in the pigment content in the leaves, while on a substrate with $\mathrm{Cr}_{10}$, it didn't.

Inoculation of plants with adapted fungal populations during their cultivation on control substrates had differences: with $\mathrm{Cr}_{2,5}$ it caused a significant increase in the content of photosynthetic pigments, and with $\mathrm{Cr}_{10}$, on the contrary, a significant decrease in their content. When cultivating plants on substrate with the addition of $\mathrm{Cr}_{2,5}$, there were 
TABLE 1: Morphological and biochemical parameters of inoculated tomato plants under conditions of different concentrations of heavy metals in the substrate

\begin{tabular}{|c|c|c|c|c|c|c|}
\hline \multirow{3}{*}{$\begin{array}{l}\text { Experience } \\
\text { options: } \\
\text { population } \\
\text { of fungi (A) / } \\
\text { Substrate (B) }\end{array}$} & \multicolumn{6}{|c|}{ Indicators } \\
\hline & \multicolumn{2}{|c|}{ biomass, $\mathrm{g}$} & \multicolumn{2}{|c|}{ dry matter content, $\%$} & \multicolumn{2}{|c|}{ biochemical parameters } \\
\hline & ground part & roots & ground part & roots & nitrates, $\mathrm{mg} / 100 \mathrm{~g}$ & $\begin{array}{l}\text { vitamin } \mathrm{C}, \mathrm{mg} / \\
100 \mathrm{~g}\end{array}$ \\
\hline Control / Zn $\mathrm{n}_{100}$ & $29,37 \pm 2,23^{*}$ & $4,70 \pm 0,28$ & $12,83 \pm 0,67$ & $7,85 \pm 0,33 \downarrow$ & $3890,43 \pm 159,98$ & $37,84 \pm 4,45 \downarrow$ \\
\hline Control / $\mathrm{Cu}_{50}$ & $25,54 \pm 0,80 \downarrow^{* *}$ & $3,81 \pm 0,24$ & $13,01 \pm 1,99$ & $5,32 \pm 1,96 \downarrow$ & $4327,69 \pm 144,58 \uparrow$ & $23,58 \pm 1,54 \downarrow$ \\
\hline Control / $\mathrm{Cu}_{100}$ & $24,31 \pm 1,86$ & $4,40 \pm 0,30$ & $12,64 \pm 0,02$ & $13,79 \pm 3,80 \uparrow$ & $5326,66 \pm 110,37 \uparrow$ & $64,62 \pm 3,57$ \\
\hline Control / $\mathrm{Cu}_{150}$ & $27.60 \pm 0,70$ & $3,63 \pm 0,24$ & $12,14 \pm 0,89$ & $13,29 \pm 1,13 \uparrow$ & $4308,72 \pm 298,07$ & $48,83 \pm 1,12 \downarrow$ \\
\hline Control / $\mathrm{Pb}_{10}$ & $24,51 \pm 1,28$ & $3,88 \pm 0,35$ & $8,85 \pm 0,50 \downarrow$ & $10,58 \pm 2,01$ & $4321,20 \pm 258,40$ & $42,43 \pm 0,55 \downarrow$ \\
\hline Control / $\mathrm{Pb}_{50}$ & $28,81 \pm 0,39$ & $3,81 \pm 0,07$ & $10,02 \pm 0,86 \downarrow$ & $8,75 \pm 1,38$ & $5014,62 \pm 466,07$ & $60,59 \pm 0,59$ \\
\hline Control / $\mathrm{Cr}_{2,5}$ & $26,87 \pm 0,35$ & $3,30 \pm 0,14 \downarrow$ & $11,74 \pm 1,87$ & $8,89 \pm 1,79$ & $4415,13 \pm 331,23$ & $46,72 \pm 3,02 \downarrow$ \\
\hline Control / $\mathrm{Cr}_{10}$ & $25,58 \pm 0,45 \downarrow$ & $4,72 \pm 0,28$ & $11,59 \pm 0,98$ & $7,75 \pm 0,18 \downarrow$ & $3213,16 \pm 96,82 \downarrow$ & $59,32 \pm 3,08$ \\
\hline $\mathrm{Zn}_{100} /$ Control & $25,58 \pm 0,73 \downarrow$ & $3,84 \pm 0,12$ & $14,92 \pm 2,32$ & $9,35 \pm 1,41$ & $3476,33 \pm 325,75$ & $53,06 \pm 2,67 \downarrow$ \\
\hline $\mathrm{Zn}_{100} / \mathrm{Zn}_{100}$ & $27,80 \pm 0,64$ & $4,72 \pm 0,45$ & $14,95 \pm 1,23$ & $11,19 \pm 2,20$ & $3585,72 \pm 606,07$ & $34,18 \pm 2,46$ \\
\hline $\mathrm{Cu}_{50} /$ Control & $23,96 \pm 1,63$ & $2,16 \pm 0,18 \downarrow$ & $10,99 \pm 1,14$ & $14,78 \pm 2,82$ & $3365,41 \pm 72,51$ & $55,48 \pm 3,54$ \\
\hline $\mathrm{Cu}_{50} / \mathrm{Cu}_{50}$ & $29,68 \pm 1,05$ & $2,13 \pm 0,23$ & $14,10 \pm 1,64$ & $15,22 \pm 2,97$ & $4638,21 \pm 346,77 \uparrow$ & $45,06 \pm 1,53$ \\
\hline $\mathrm{Cu}_{100} /$ Control & $19,82 \pm 0,40 \downarrow$ & $2,30 \pm 0,15 \downarrow$ & $10,91 \pm 1,64$ & $13,17 \pm 2,43$ & $4837,86 \pm 206,82$ & $49,83 \pm 3,69$ \\
\hline $\mathrm{Cu}_{100} / \mathrm{Cu}_{100}$ & $35,29 \pm 0,25 \uparrow$ & $2,39 \pm 0,69$ & $12,67 \pm 0,82$ & $12,68 \pm 2,45$ & $3534,60 \pm 99,78$ & $52,70 \pm 5,29$ \\
\hline $\mathrm{Cu}_{150} /$ Control & $27,99 \pm 0,81$ & $1,93 \pm 0,04 \downarrow$ & $9,44 \pm 1,79$ & $16,10 \pm 3,80$ & $3058,14 \pm 25,50 \downarrow$ & $39,20 \pm 4,92 \downarrow$ \\
\hline $\mathrm{Cu}_{150} / \mathrm{Cu}_{150}$ & $24,16 \pm 1,12$ & $2,23 \pm 0,18$ & $12,26 \pm 1,21$ & $13,25 \pm 2,73$ & $4487,60 \pm 103,26 \uparrow$ & $32,57 \pm 4,80$ \\
\hline $\mathrm{Pb}_{10} /$ Control & $32,66 \pm 2,01$ & $2,98 \pm 0,15 \downarrow$ & $13,67 \pm 1,92$ & $10,24 \pm 0,65$ & $3356,96 \pm 241,51$ & $46,72 \pm 2,28 \downarrow$ \\
\hline $\mathrm{Pb}_{10} / \mathrm{Pb}_{10}$ & $26,30 \pm 0,87$ & $2,36 \pm 0,22$ & $11,41 \pm 1,09$ & $11,71 \pm 1,01$ & $4488,58 \pm 102,55 \uparrow$ & $51,93 \pm 1,64$ \\
\hline $\mathrm{Pb}_{50} /$ Control & $21,88 \pm 1,31 \downarrow$ & $1,55 \pm 0,10 \downarrow$ & $12,39 \pm 1,36$ & $10,98 \pm 1,16$ & $3986,02 \pm 82,59$ & $62,36 \pm 2,98$ \\
\hline $\mathrm{Pb}_{50} / \mathrm{Pb}_{50}$ & $28,16 \pm 1,30$ & $2,49 \pm 0,36$ & $12,92 \pm 1,16$ & $10,01 \pm 1,17$ & $4229,96 \pm 177,36$ & $48,05 \pm 0,90 \downarrow$ \\
\hline $\mathrm{Cr}_{2,5} /$ Control & $21,59 \pm 2,04 \downarrow$ & $1,92 \pm 0,08 \downarrow$ & $12,24 \pm 0,26$ & $11,38 \pm 1,85$ & $4384,27 \pm 195,22$ & $47,81 \pm 3,02 \downarrow$ \\
\hline $\mathrm{Cr}_{2,5} / \mathrm{Cr}_{2,5}$ & $29,54 \pm 0,09 \uparrow$ & $2,50 \pm 0,01 \uparrow$ & $13,16 \pm 0,61$ & $9,52 \pm 1,49$ & $4161,79 \pm 494,02$ & $71,09 \pm 0,80 \uparrow$ \\
\hline $\mathrm{Cr}_{10} /$ Control & $16,36 \pm 0,94 \downarrow$ & $1,56 \pm 0,15 \downarrow$ & $13,12 \pm 1,98$ & $14,17 \pm 2,00$ & $5188,76 \pm 622,04$ & $50,53 \pm 1,66 \downarrow$ \\
\hline $\mathrm{Cr}_{10} / \mathrm{Cr}_{10}$ & $27,30 \pm 0,26 \uparrow$ & $2,06 \pm 0,22$ & $14,23 \pm 2,73$ & $11,90 \pm 1,12$ & $3583,89 \pm 471,03$ & $64,82 \pm 7,75$ \\
\hline Control / Control & $29,30 \pm 0,70$ & $5,44 \pm 0,63$ & $15,33 \pm 2,02$ & $9,46 \pm 0,15$ & $3693,55 \pm 87,76$ & $63,48 \pm 2,50$ \\
\hline
\end{tabular}

no significant changes observed, and only when $\mathrm{Cr}_{10}$ was added, a decrease in the content of chlorophyll $a$ and carotenoids was observed in the absence of significant differences with the control in the content of chlorophyll $b$.

When plants were inoculated with a control fungus population and cultured on a substrate with $\mathrm{Cr}_{10}$, we observed a decrease in the indicators of the top biomass, the percentage of dry matter in the root system of plants and nitrates in the leaves. The results are of interest in variants using plant inoculation with adapted fungal populations: when cultivating plants on control substrates, we observed a decrease in the biomass of 
the aerial part and root system of plants, but when plants were cultivated on substrates with chromium, on the contrary, there was an increase in plant biomass.

In variants with chromium the use of adapted fungus populations led to the highest rates of development of fungal infection in the root of the plants, with the highest rates at the highest chromium content in the substrate $\left(\mathrm{Cr}_{10} / \mathrm{Cr}_{10}\right.$ variant).

The results of our studies using non-biogenic chemical elements hazardous to plant life are consistent with the opinion of a number of scientific publications $[6,10,12]$ about the peculiar form of partnership of endotrophic fungi with the root system of plants: the protective effect of fungi is most effective in conditions unfavorable for plant life.

In all variants with zinc addition the pigment content in the leaves of plants had common patterns: inoculation of plants with a control population $(A 0)$ when grown on a substrate with zinc did not have any effect on the content of photosynthetic pigments; inoculation of plants by adapted populations when grown on a control substrate (BO) caused a significant increase in the content of chlorophylls $a$ and $b$, carotenoids, and when grown on a substrate with zinc, on the contrary, a significant, almost two times, decrease in the content of pigments was observed. As for the other studied parameters (table), inoculation of the control population when growing plants on a substrate with zinc led to a significant decrease in the dry matter content in the root system of plants. Inoculation with adapted populations of the fungus caused a true decrease in the top biomass of plants (when grown on a control substrate) and did not affect the studied parameters of plants when cultivated on a substrate with zinc.

High rates of development of fungal infection of $C$. magnusianum in the root system of plants were noted in the control population $/ \mathrm{Zn}_{100}$ variant (table), while using adapted populations the fungal infection was less developed, especially in the $Z n_{100} / Z_{100}$ variant.

In variants with $\mathrm{Cu}_{100}$, an increase in the content of chlorophylls $a$ and $b$ was found when using adapted populations, while inoculation with the control population, on the contrary, led to a significant sharp decrease in the content of pigments. In variants with the maximum copper content $\left(\mathrm{Cu}_{150}\right)$ we did not reveal changes in the content of carotenoids, but the use of adapted populations led to an increase in the content of chlorophylls.

The results of the analysis of other studied plant parameters showed that inoculation of plants with the control fungus population led to an increase in the content of nitrates in the leaves in variants of substrates with $\mathrm{Cu}_{50}$ and $\mathrm{Cu}_{100}$, as well as to an increase in the percentage of dry matter in the root system of plants in variants with $\mathrm{Cu}_{100}$ and $\mathrm{Cu}_{150}$. This is consistent with data on the effect of inoculation on plants exposed to 
$\mathrm{HM}$, associated with the change in the root system architecture and the accumulation of total nitrogen [12]. The use of adapted fungal populations in the cultivation of inoculated plants on a control substrate led to a decrease in biomass of the root system, and in variant with $\mathrm{Cu}_{150}$, to a decrease in the content of nitrates in the leaves. When inoculated with adapted fungal populations on substrates with the addition of $\mathrm{Cu}_{50}$ and $\mathrm{Cu}_{150}$, a significant increase in the content of nitrates in the leaves was noted, and with $\mathrm{Cu}_{100}$, an increase of the top biomass of plants.

The most intensive fungal infection was formed using adapted $\mathrm{Cu}_{100}$ and $\mathrm{Cu}_{150}$ populations. The maximum development of fungal infection was noted in the $\mathrm{Cu}_{100} / \mathrm{Cu}_{100}$ variant.

\section{Conclusion}

The results of studies showed that the content of chlorophylls $a$ and $b$ turned out to be the most sensitive indicator of plants on the inoculation effect. Inoculation with the control population of the fungus did not contribute to the formation of adaptive reactions in plants, which was manifested in a decrease in the content of photosynthetic pigments and a number of other studied plant parameters when they were cultivated on substrates with the addition of heavy metal salts.

In variants with non-biogenic elements adaptive reactions of plants were most significantly manifested during inoculation of plants by adapted fungus populations and upon further cultivation of plants on substrates with the addition of chromium and lead salts. This fact may indicate the most effective partnership of $C$. magnusianum and plants under stress.

The fungal infection in the roots of plants in all variants of the experiment was quite well developed. The use of $C$. magnusianum isolates adapted to the action of chromium salts for plant inoculation upon their further cultivation on substrates with the addition of chromium salts stimulated the development of fungal infection in the plant root.

Inoculation of plants with adapted populations had a positive effect: for $\mathrm{Cu}_{100}$ and $\mathrm{Cu}_{150}$ variants, moreover, when they were grown on both control and substrates with copper; for $\mathrm{Zn}_{100}$ - only when cultivating plants on a control substrate.

\section{Acknowledgements}

This work was supported by the grant of the Russian Foundation for Basic Research "Postgraduate Student" No. 19-31690003. 


\section{Abbreviations}

AM - arbuscular mycorrhiza

AMF - arbuscular mycorrhizal fungi

DNA - deoxyribonucleic acid

$\mathrm{HM}$ - heavy metal salts

GOST - state standard for analysis

\section{Declarations}

Ethics approval and consent to participate

Not applicable.

Consent for publication

Not applicable.

Availability of data and material

The materials of research and associated plants attributes used in the study are available from the corresponding author on reasonable request.

Competing interests

The authors declare that they have no conflicts and competing interests.

Funding

The research was supported by a grant from the Russian Fund for Fundamental Research "Graduate Student" No. 19-34-50037.

Authors' contributions

Bukharina Irina - research management, development of the scheme and methods of the experiment, analysis of the results, writing the text of the article.

Islamova Nadezhda - experimental work, statistical processing and analysis of the results, the design of tables and figures.

Authors' information

Bukharina Irina: Doctor of Biological Sciences, Professor, Udmurt State University, Izhevsk, Russia, buharin@udmlink.ru.

Islamova Nadezhda: graduate student, Udmurt State University, Izhevsk, Russia, islamovanadezhda@mail.ru 


\section{References}

[1] Yurkov AP, Kryukov AA, Gorbunova AO et al. Molecular genetic identification of arbuscular mycorrhiza fungi. Ecological Genetics. 2018; 16(2):11-23. doi: 10.17816 / ecogen16211-23 (Ru).

[2] Ijdo M, Cranenbrouck S, Declerck S. Methods for large-scale production of AM fungi: Past, present and future. Mycorrhiza. 2011;21:1-16. doi: 10.12691/ijebb-4-1-1

[3] Rodriguez RJ, White JF, Arnold AE, Redman RS. Fungal endophytes: Diversity and functional roles. New Phytologist. 2009;182:314-330. doi:10.1111/j.14698137.2009.02773.x.

[4] El-Samad HM, El-Hakeem KNS. Strategy role of mycorrhiza inoculation on osmotic pressure, chemical constituents and growth yield of maize plant gown under drought stress. American Journal of Plant Sciences. 2019;10(6):1102-1120. DOI: 10.4236/ajps.2019.106080

[5] Ikram M, Ali IN, Jan G et al. IAA producing fungal endophyte Penicillium roqueforti Thom., enhances stress tolerance and nutrients uptake in wheat plants grown on heavy metal contaminated soils. Plos One. 2018;29:2-22. https://doi.org/10.1371/journal.pone.0208150

[6] Bilal S, Shahzad R, Khan AL, Al-Harrasi A, Kim CK, Lee I.-J. Phytohormones enabled endophytic Penicillium funiculosum LHL06 protects Glycine max L. from synergistic toxicity of heavy metals by hormonal and stress-responsive proteins modulation. Journal of Hazardous Materials. 2019;379:120824.

[7] Dabral S, Varma YA, Choudhary DK, Bahuguna RN, Nath M. Biopriming with Piriformospora indica ameliorates cadmium stress in rice by lowering oxidative stress and cell death in root cells. Ecotoxicology and Environmental Safety. 2019;186:1-12.

[8] Ali A, Bilal S, Khan AL, Mabood F, Al-Harrasi A, Lee I.-J. Endophytic Aureobasidium pullulans BSS6 assisted developments in phytoremediation potentials of Cucumis sativus under Cd and Pb stress. Journal of Plant Interactions. 2019;14(1):303-313.

[9] Bilal S, Shahzad R, Imran M, Jan R, Min K, Lee I.-J. Synergistic association of endophytic fungi enhances Glycine max L. resilience to combined abiotic stresses: Heavy metals, high temperature and drought stress. Industrial Crops \& Products. 2020;143:1-10.

[10] Li X, Zhang X, Wang X, Yang X, Cui Z. (2019). Bioaugmentation-assisted phytoremediation of lead and salinity co-contaminated soil by Suaeda salsa and Trichoderma asperellum. Chemosphere. 2019;224:716-725. 
[11] Sharma VK, Li X, Wu G, Bai W, Parmar S, White Jr JF, Li H. Endophytic community of $\mathrm{Pb}-\mathrm{Zn}$ hyperaccumulator Arabis alpina and its role in host plants metal tolerance. Plant Soil. 2019;437:397-411. https://doi.org/10.1007/s11104-019-03988-0

[12] Hou L, Yu J, Zhao L, He X. Dark septate endophytes improve the growth and the tolerance of Medicago sativa and Ammopiptanthus mongolicus under cadmium stress. Frontiers in Microbiology. 2020;10:1-17. doi: 10.3389/fmicb.2019.03061

[13] Sogonov MV, Velikanov LL. Soilmicrofungi from alpine and subnival ecosystems of the Northwestern Caucasus. Mikologiya I Fitopatologiya. 2004;38(3):50-58.

[14] Boyette CD, Hoagland RE, Stetina KC. Efficacy improvement of a bioherbicidal fungus using a formulation-based approach. American Journal of Plant Sciences. 2016;7(16):2349-2358. DOI: 10.4236/ajps.2016.716206

[15] Boyette CD, Hoagland RE, Stetina KC. Hot water treatment enhances the bioherbicidal efficacy of a fungus. American Journal of Plant Sciences. 2018;9(10):2063-2076. DOI: 10.4236/ajps.2018.910150

[16] Meepagala KM, Clausen BM, Johnson RD, Wedge DE, Duke SO. A phytotoxic and antifungal metabolite (Pyrichalasin h) from a fungus infecting Brachiaria eruciformis (signal grass). Journal of Agricultural Chemistry and Environment. 2019;8(3):115-128. DOI: $10.4236 /$ jacen.2019.83010

[17] Sobowale AA. Probable effects of dual inoculation of maize (Zea mays) stem with Fusarium verticillioides and certain Trichoderma species on fumonisin content of maize seeds. American Journal of Plant Sciences. 2019;10(5):752-759. DOI: 10.4236/ajps.2019.105055

[18] Amaral DR, Oliveira DF, Campos VP, de Carvalho DA, Nunes AS. Effect of plant and fungous metabolites on Meloidogyneexigua. Ciencia e Agrotecnologia. 2009;33:1861-1865. doi: 10.1590/S1413-70542010000500021

[19] Bukharina IL, Islamova NA. Study of the stability limits of microscopic fungi and the formation of a collection of promising isolates. Material annual meeting of the society of plant physiologists in Russia "Plant signaling systems: from the receptor to the body's response". MODERN PROBLEMS OF SCIENCE AND EDUCATION 2015. 3. 362-363.

[20] Bukharina IL, Islamova NA. Investigation of the metal resistance of isolates of microscopic fungi. Presented at: Experimental Plant Biology: Fundamental and Applied Aspects: Annual Meeting of the Society of Plant Physiologists of Russia; 2017 September 18-24; Sudak, Russia.

[21] Bukharina I, Franken P, Kamasheva A, Vedernikov K, Islamova N. About the species composition of microscopic fungi in soils and woody plant roots in 
urban environment. International Journal of Advanced Biotechnology and Research. 2016;7(4):1386-1394.

[22] Stark OY, Labutova NM. Traditional methods of working with arbuscular mycorrhizal fungi. SPb: GNU VNIISCHM; 2014. 